\title{
Contamination of Camel Milk (Heavy Metals, Organic Pollutants and Radionuclides) in Kazakhstan
}

\author{
Gaukhar Konuspayeva ${ }^{1}$, Stefan Jurjanz ${ }^{2}$, Gerard Loiseau ${ }^{3}$, Vincent Barci ${ }^{4}$, Shynar Akhmetsadykova ${ }^{1,3,5}$, \\ Aliya A. Meldebekova ${ }^{1}$, Bernard Faye ${ }^{5}$ \\ ${ }^{1}$ Al Farabi Kazakh National University, Al Farabi, Almaty, Kazakhstan; ${ }^{2}$ USC INRA/Nancy Université: Animal et Fonctionnalités \\ des Produits Animaux, Vandoeuvre cedex, France; ${ }^{3}$ UMR Qualisud, CIRAD, Montpellier, France; ${ }^{4}$ Université de Nice Sophia- \\ Antipolis, Laboratoire de Radiochimie, Nice cedex, France; ${ }^{5}$ CIRAD-Département Environnements et Sociétés, Campus Interna- \\ tional de Baillarguet, Montpellier, France. \\ Email: konuspayevags@hotmail.fr, faye@cirad.fr
}

Received September $8^{\text {th }}, 2010$; revised November $3^{\text {rd }}, 2010$; accepted December $17^{\text {th }}, 2010$.

\begin{abstract}
In Kazakhstan, camel breeding mainly occupies areas sometimes close to polluting industries or other sources of pollution as industrial agriculture, mainly cotton. Products issued from camel farms close to these sources as camel raw milk and fermented milk (shubat), wool and meat, traditionally used by humans could be contaminated. We investigated camel raw milk and fermented milk for the content of heavy metals (lead, cadmium, zinc and copper), radionuclide and some organic pollutants (PAHs, pesticides and indicator PCBs) in samples from different regions with a priori high risk of pollution (Atyrau, Kyzylorda, South-Kazakhstan and Almaty region). In the present paper, only some milk samples presented high lead concentration (>500 ppb). After analysis for organic pollutants, it was observed some traces of hexachlorocyclohexane, lindane, hexanchlorothalonil in milk samples from different regions. One sample was also slightly contaminated with radionuclide. These preliminary results allow establishing a first map of risk for camel farming. As the whole, South-Kazakhstan appeared the most exposed region.
\end{abstract}

Keywords: Camel Milk, Pollutant, Heavy Metal, Pesticides, Radionuclides

\section{Introduction}

The consumption of camel milk is very popular in Kazakhstan where it is known for its medicinal and dietary properties [1]. These properties are widely exploited for human health, as it is in several countries from the ex-Soviet Union and developing countries [2,3]. But nowadays, the country is immersed in an "ecological crises", due to the specific place for nuclear test by soviet government for long a time, and to the development of irrigation for cotton field linked with decreasing Aral Sea level. In addition, the manufacturing of metals and the minerals had high impact on environmental contamination, few control of rejecting contaminants being implemented. In those conditions, milk producing camels can be exposed to several indesirable compounds. Some references on heavy metals content in cow and breast milk are available $[4,5]$. But concerning sheep and goat milk there are few references, and none on camel milk.
In Kazakhstan, camel breeding occupies areas sometimes close to polluting industries or other sources of pollution as industrial agriculture (mainly cotton) or highly frequented traffic ways. Products issued from camel farms close to these sources as camel milk and shubat (fermented product), can come into the Human food chain via dairy products. Indeed, Kazakh habitants consume on average $210 \mathrm{~kg}$ of milk and dairy products per year what make them quite exposed if camel milk would be polluted. In such case, concerns of public health may arise and need to be integrated in the risk management.

Also, in Kazakhstan, lead, copper, iron, zinc and cadmium are currently used in industrial process, and PCBs are often linked to an industrial waste discharged in the environment. Pesticides are used in industrial agriculture and radionuclides are linked to the nuclear sites or wastages.

In the present paper, pollutant residues (heavy metals 
as copper, zinc, lead and cadmium, radionuclides as cesium $^{137}$ and organic pollutants) are investigated in raw and fermented milk from different regions with high risk of pollution (Almaty, Atyrau, Kyzylorda, Zhambyl and South-Kazakhstan region).

\section{Material and Methods}

\subsection{Sampling Procedure}

The sampling procedures were achieved in 24 farms where camel raw milk (herd mixed milk) and fermented milk (shubat) processed within farm were collected. They belonged to 4 oblasts (regions) chosen for their potentially contaminated environment: Almaty, Kyzylorda, Atyrau, and South-Kazakhstan oblasts. Samples were taken from dromedary camels (one hump), Bactrian camels (two humps) and hybrids camels. The contaminating sources, as manufacturing, oil forages and spatial base were identified: in Almaty region, some exhaust gases near biggest city; in Atyrau region, oil forage, and in Kyzylorda region the spatial base of Baikanour, small asphalt factory; in South-Kazakhstan and Zhambyl region, polymetal industries and phosphate manufacturing (Kengtaw, Aca, Karatau) and cotton field (Figure 1). According to importance of potential pollution by heavy metals in Zhambyl area, the heavy metals analysis in milk included this fifth region, contrary to the other parameters limited to four regions.

In the present study for radionuclide content, 20 samples of raw camel milk and 16 samples of lyophilized camel milk were analyzed in order to evaluate the rate in ${ }^{137} \mathrm{Cs}$ by detection of gamma radiation (Nice University). Those samples came also from four regions of Kazakhstan (Atyrau, Aralsk, Shymkent and Almaty) at various distances from nuclear test areas.

\subsection{Heavy Metals Determination}

The analysis of heavy metals and trace elements in milk and shubat were achieved in two steps:

Mineralisation by wet oxidation to destroy the organic matter in presence of nitric, sulphuric and perchloric acids. The advantage of this method, compared to the dry way method, is the lack of volatile elements loss. Ten $\mathrm{ml}$ of milk sample was added with nitric acid reagent $65 \%$ (Carlo Erba Reagents SA). Then the mixture was placed in a ceramic capsule on a heating plate up to $500^{\circ} \mathrm{C}$ for 4 hours. Nitric acid $65 \%$ was added again on the ashes then evaporated on the heating plate up to the total destruction of the organic matter. When the solution was white, the solution was diluted up to $10 \mathrm{ml}$ with distilled water containing $1 \%$ nitric acid.

This analysis was achieved by ICP methods (Inductively Coupled argon Plasma-Atomic Emission Spectrometer
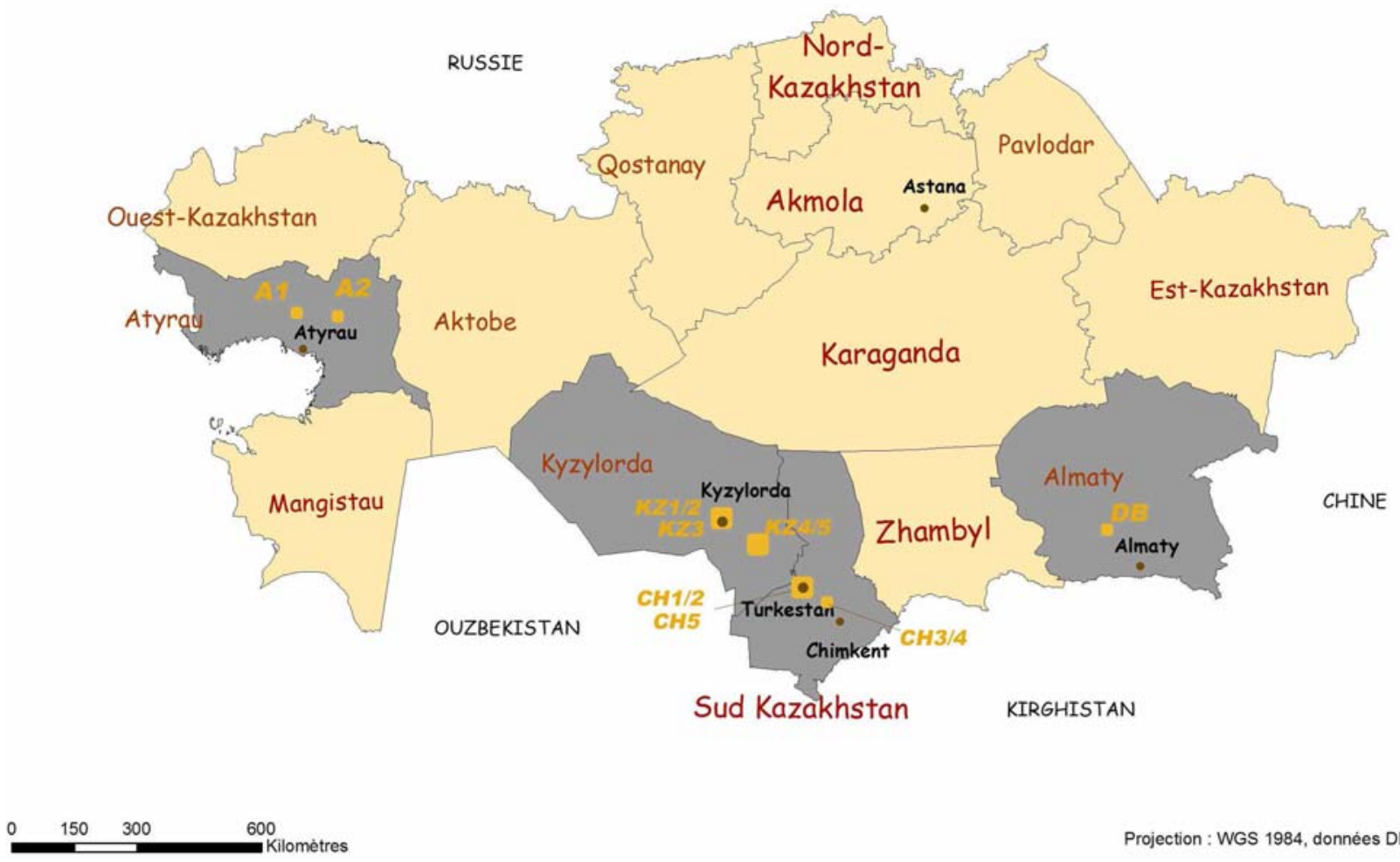

Projection : WGS 1984, données DIVA GIS

Figure 1. Map of sampling sites of camel milk and shubat in Kazakhstan. 
(ICP AES), Varian Vista MPX-CCD), in laboratory of CIRAD-UR Qualisud (Montpellier-France). The quantification of the elements was performed by the standard addition method, using 11 point standard curve. AccuTraceTM Reference Standard solutions used were Quality Control Standard \#1Accu Standard ${ }^{\circledR}$ and Laboratory Performance Check Standard AccuStandard®.

\subsection{Pesticides Determination}

The pesticides and indicator PCBs in milk are determined after extraction of the fat matter by gas chromatography following a normalized procedure [6].

PAHs and their hydroxylated metabolites are analyzed as previously published for cow and goat milk [7]. According to the high cost of analysis of all organic pollutants and the large number of molecules involved, analysises were performed on mixed milk from 4 regions (Atyrau, Kyzylorda, Zhambyl and South-Kazakhstan regions).

\subsection{Radionuclides Determination}

For the analyze of radionuclides, a $\gamma$-radio detector HPGe vertical, was used with a standard for liquid samples: $137 \mathrm{Cs}$ accounted in similar plastic bottle than those containing the camel milk sample, matrix $86.60 \mathrm{~g}$ solution, reference activity of the standard being, ${ }^{137} \mathrm{Cs}(\mathrm{T} 1 / 2=$ 30.7 a) $88.6 \pm 1.5 \mathrm{~Bq}$; time accounting: $250000 \mathrm{~s}$; comparison of accounting rate for ${ }^{137} \mathrm{Cs}$, gamma $661.657 \mathrm{keV}$ [8]. These analyses included all individual milk samples from the fourth retained regions as mentioned above, but not the shubat.

\subsection{Statistical Analysis}

Descriptive statistics were carried out (mean and standard deviation) for each heavy metal. Simple variance analysis was performed for assessing the region effect. Correlations between values in milk and shubat were assessed by the Pearson correlation test when it was justified.

Concentrations of PAHs were analysed by graphic representation of their profil at each site. Nevertheless, the results of pesticides and indicator PCBs were summarized in a first step by the frequency of concentrations overstepping the analytical thresholds. A second step compared obtained concentrations.

\section{Results}

The results are given for each type of pollutants (heavy metals, organic pollutants, radionuclides).

\subsection{Heavy Metals}

The concentrations in heavy metals in the four oblasts of Kazakhstan: (Almaty, Atyrau, Kyzylorda, Zhambyl and
South-Kazakhstan) were on average very low for copper (less than $0.05 \mathrm{ppm}$ ), normal in zinc (around $5 \mathrm{ppm}$ ) and cadmium, but slighty high for lead (Table 1).

The variance analysis showed significant higher values in Almaty compared to other regions for all the parameters except zinc, both in milk and shubat, and cadmium in shubat. Lead was also significantly higher in SouthKazakhstan (shymkent area) compared to Kyzylorda, Zhambyl and Atyrau region both in milk and shubat. A slight significant difference was observed for zinc in milk between Kyzylorda and the other regions.

According to the correlation matrix, few significant correlation were observed between element cadmium and lead in the milk, but the concentrations in zinc, lead and cadmium were highly correlated to the same parameters in shubat (Table 2).

\subsection{Organic Pollutants}

Organic pollutants were quantified only in camel milk from regions representing risks due to existing emitting sources (Atyrau, Kyzylorda, Zhambyl and South-Kazakhstan).

Several compounds of PAHs were not found in camel milk. Indeed, concentrations of Anthracene, Cyclopenta $[\mathrm{c}, \mathrm{d}]$ pyrène, Dibenzo $[\mathrm{a}, \mathrm{e}]$ pyrène, Dibenzo $[\mathrm{a}, \mathrm{i}]$ pyrène, Dibenzo $[\mathrm{a}, \mathrm{h}]$ pyrène, Dibenzo $[\mathrm{a}, \mathrm{l}]$ pyrène and Benzo [c] fluorine were under the quantification limit and no hydroxylated metabolite of phenanthrene, pyrene or benzo [a] pyrene was revealed. The profil of the 13 remaining PAH compounds showed occurrence of the lightest compounds (phenanthrene, fluorenthene and pyrene) as well as traces of intermediate and heavy compounds (Figure 2). Occurrence and concentrations of compounds in camel milk collected in the region of Atyrau (WestKazakhstan) were sometimes absent or lower in comparison to milk from South-Est Kazakhstan (Zhambyl and Shymkent). Camel milk from the region Kyzylorda shows a different profil: nearly all parent PAHs are present but lightest compounds are in lower concentrations in comparison to South-East Kazakhstan.

Indicator PCBs were only revealed in milk from the Kyzylorda oblast but at a low level $(0.95 \mathrm{ng} / \mathrm{g})$, and mainly PCBs 52 and 138 . With a daily consumption of $630 \mathrm{~g}$ of milk/habitant, the DJT would be $600 \mathrm{ng} / \mathrm{man}$ on average.

Analysis of pesticides shows presence of HCHs (beta, delta, and only in the Kyzylorda oblast also gamma $\mathrm{HCH}$ ). Moreover, DDT was found in milk from the Kyzylorda oblast $(0.8 \mu \mathrm{g} / \mathrm{kg})$ and Chlorothalonil in milk of the cotton area of Shymkent $(0.5 \mu \mathrm{g} / \mathrm{kg})$.

Thus, pesticides are absent in West-Kazakhstan (Atyrau oblast) but different compounds were revealed in milk 
Table 1. Mean value and SD of the copper, zinc, lead and cadmium content of camel milk and shubat per 5 regions of Kazakhstan (in ppm).

\begin{tabular}{|c|c|c|c|c|c|c|c|c|}
\hline \multirow{2}{*}{ Regions } & \multicolumn{2}{|c|}{$\mathrm{Cu}$} & \multicolumn{2}{|c|}{$\mathrm{Zn}$} & \multicolumn{2}{|c|}{$\mathrm{Pb}$} & \multicolumn{2}{|c|}{$\mathrm{Cd}$} \\
\hline & Milk & Shubat & Milk & Shubat & Milk & Shubat & Milk & Shubat \\
\hline Almaty & $0.07^{\mathrm{a}}$ & $0.06^{\mathrm{a}}$ & 4.90 & 5.50 & $0.06^{\mathrm{a}}$ & $0.06^{\mathrm{a}}$ & $0.003^{\mathrm{a}}$ & 0.003 \\
\hline Atyrau & $<0.05^{\mathrm{b}}$ & $<0.05^{\mathrm{b}}$ & $4.75^{\mathrm{b}}$ & 6.50 & $<0.01^{\mathrm{c}}$ & $<0.01^{\mathrm{a}}$ & $<0.001^{\mathrm{b}}$ & $<0.001$ \\
\hline Kyzylorda & $<0.05^{\mathrm{b}}$ & $<0.05^{\mathrm{b}}$ & $5.31^{\mathrm{a}}$ & 5.70 & $0.02^{\mathrm{c}}$ & $0.02^{\mathrm{a}}$ & $<0.001^{\mathrm{b}}$ & $<0.001$ \\
\hline Zhambyl & $<0.05^{\mathrm{b}}$ & $<0.05^{\mathrm{b}}$ & $4.85^{\mathrm{b}}$ & 4.50 & $0.01^{\mathrm{c}}$ & $0.01^{\mathrm{a}}$ & $<0.001^{\mathrm{b}}$ & $<0.001$ \\
\hline South-Kaz. & $<0.05^{\mathrm{b}}$ & $<0.05^{\mathrm{b}}$ & $4.07^{\mathrm{b}}$ & 4.16 & $0.04^{\mathrm{b}}$ & $0.04^{\mathrm{c}}$ & $0.002 b$ & 0.002 \\
\hline Region Effect & $P<0.05$ & $P<0.001$ & NS & NS & $P<0.001$ & $P<0.005$ & NS & NS \\
\hline Root MSE & 0.007 & 0.002 & 1.115 & 1.593 & 0.013 & 0.014 & 0.001 & 0.001 \\
\hline Total mean & $0.05 \pm 0.01$ & $0.05 \pm 0.03$ & $4.70 \pm 1.16$ & $5.06 \pm 1.59$ & $0.03 \pm 0.02$ & $0.03 \pm 0.02$ & $0.002 \pm 0.001$ & $0.002 \pm 0.001$ \\
\hline
\end{tabular}

a,b, the different letters expressed the significant differences at least at $P<0.05$.

Table 2. Correlation matrix between the heavy metals in milk (L) and shubat (S). The significant values (p $>0.05)$ were in bold character.

\begin{tabular}{|c|c|c|c|c|c|c|c|c|}
\hline Variables & $\mathrm{CuL}$ & $\mathrm{ZnL}$ & $\mathrm{PbL}$ & $\mathrm{CdL}$ & $\mathrm{CuS}$ & $\mathrm{ZnS}$ & $\mathrm{PbS}$ & $\mathrm{CdS}$ \\
\hline $\mathrm{CuL}$ & 1 & -0.082 & 0.397 & 0.109 & 0.203 & -0.114 & 0.120 & -0.143 \\
\hline $\mathrm{ZnL}$ & -0.082 & 1 & -0.037 & -0.167 & 0.021 & 0.606 & -0.174 & 0.026 \\
\hline $\mathrm{PbL}$ & 0.397 & -0.037 & 1 & 0.606 & 0.351 & -0.193 & 0.737 & 0.639 \\
\hline $\mathrm{CdL}$ & 0.109 & -0.167 & 0.606 & 1 & 0.354 & -0.308 & 0.477 & 0.458 \\
\hline $\mathrm{CuS}$ & 0.203 & 0.021 & 0.351 & 0.354 & 1 & 0.016 & 0.389 & 0.321 \\
\hline $\mathrm{ZnS}$ & -0.114 & 0.606 & -0.193 & -0.308 & 0.016 & 1 & -0.094 & 0.004 \\
\hline $\mathrm{PbS}$ & 0.120 & -0.174 & 0.737 & 0.477 & 0.389 & -0.094 & 1 & 0.677 \\
\hline $\mathrm{CdS}$ & -0.143 & 0.026 & 0.639 & 0.458 & 0.321 & 0.004 & 0.677 & 1 \\
\hline
\end{tabular}

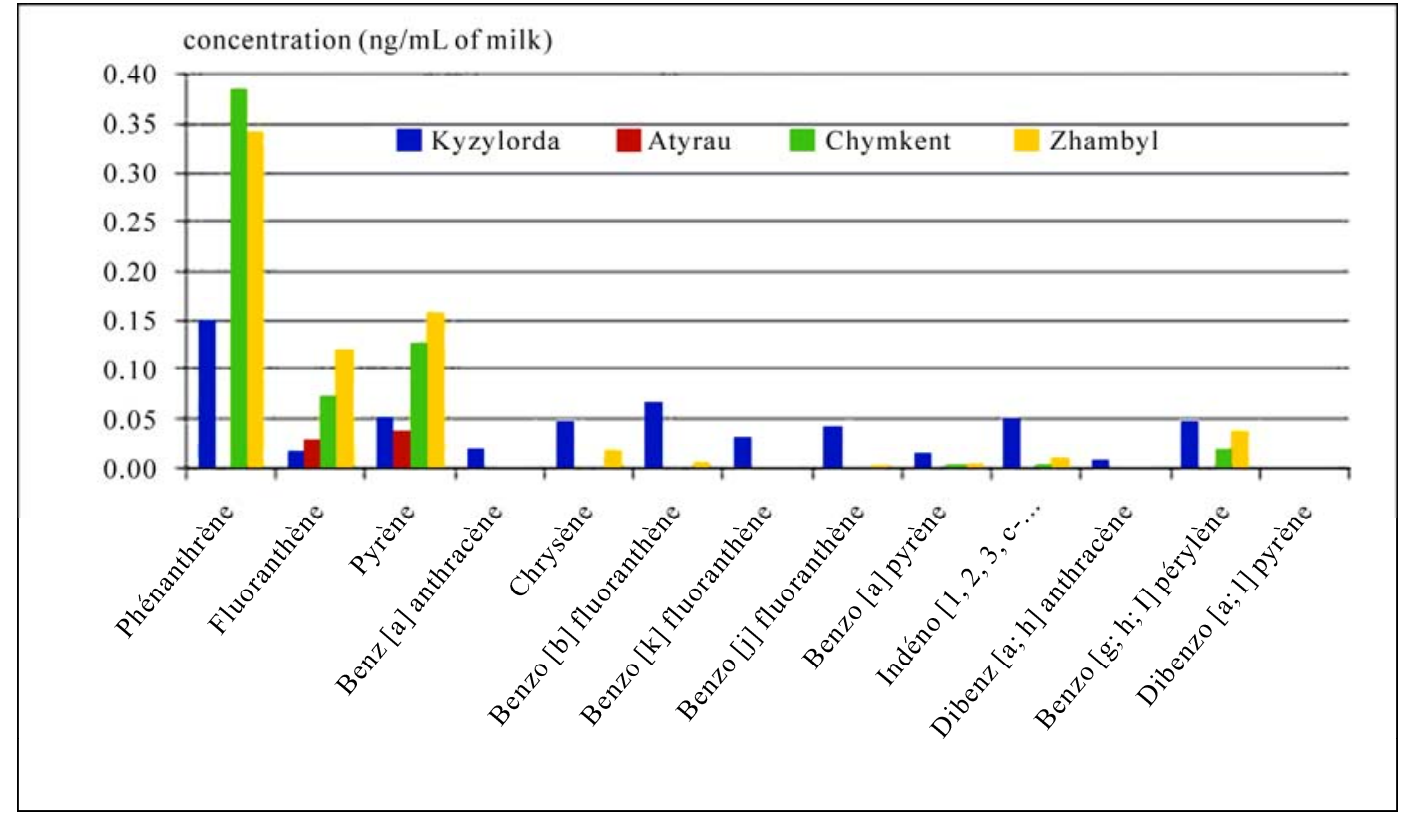

Figure 2. Concentration of different PAHs in camel milk collected in different regions of Kazakhstan. 
sampled in South Kazakhstan, especially in the cotton areas Shymkent and Kyzylorda. Contamination of camel milk collected in the Zhambyl region showed an intermediate number of pesticides present in milk (only gamma and delta $\mathrm{HCHs}$ ).

\subsection{Radionuclides}

If we consider the limit at $95 \%$ confidence, a single sample from South-Kazakhstan region had detectable activity $(0.294 \pm 0.076 \mathrm{~Bq} / \mathrm{kg})$, but at $90 \%$ confidence interval, 2 samples of raw milk and 7 samples of powder milk had also a detectable radiological activity $(>0.028 \mathrm{~Bq})$. Those samples came mainly from South-Kazakhstan oblasts.

\section{Discussion}

According to the literature, human activities close to the sampling area influence the concentration of heavy metals in milk. Especially, traffic road intensity plays a role on lead content in cow milk. The lead content in milk was positively correlated to the traffic density, (from $0.36 \mathrm{ppm}$ on average for a traffic density of 10 vehicles per day to $7.20 \mathrm{ppm}$ on average for a traffic density of 15000 vehicles per day) [9]. Lead concentration in cow milk was on average of $0.00132 \mathrm{ppm}$ in rural area and of $0.25 \mathrm{ppm}$ in industrial area and $0.032 \mathrm{ppm}$ close a road [10-12]. In Germany and Holland, higher value allowed is $0.05 \mathrm{ppm}$ of $\mathrm{Pb}$ in milk; $0.02 \mathrm{ppm}$ in Turkey and 0.1 $\mathrm{ppm}$ in Kazakhstan. In industrial area, lead concentration of cow milk varied from $0.049 \mathrm{ppm}$ to $0.067 \mathrm{ppm}$, with higher mean value of $0.844 \mathrm{ppm}$ near zinc and lead smelter [12-14].

Concerning others heavy metals, few references were available. Zinc content in milk seems to be in the normal range even in animals reared near industrial or traffic areas, Although, milk from industrial contained significantly more zinc than in traffic and rural area, $5.01 \mathrm{ppm}$, $4.49 \mathrm{ppm}$ and $3.77 \mathrm{ppm}$ respectively [12].

For copper, observations were similar: the proximity of industrial area increased significantly the copper concentration in cow milk as well as traffic area, cow milk from rural area containing less copper $(0.96 \mathrm{ppm}, 0.58$ ppm et $0.39 \mathrm{ppm}$ respectively) [12].

It was impossible to attest if lead contamination of camel milk was important or not, as no reference was available. Reported values in our sample were on average higher than the tolerable value of $0.02 \mathrm{ppm}$ proposed in Turkey, but under the normal value of $0.05 \mathrm{ppm}$ considered in Germany and Holland and $0.1 \mathrm{ppm}$ in Kazakhstan. However, in some farms, the values could overpass 0.05 ppm especially at Almaty and South-Kazakhstan. Bhati and Choudhry (1996), Dey and Swarup (1996) and Simsek et al., (2000) considered that cattle reared close to manufacturing or roads produced a milk containing significantly higher levels of lead $[9,12,13]$. However, in all these studies, lead concentration in milk was very variable, with higher value between $0.032 \mathrm{ppm}$ and $7.20 \mathrm{ppm}$ $[9,14]$. Taking in consideration all these informations, it was possible that the highest lead concentration in milk from some farms could be due to the proximity of road with high traffic.

Very few references were available on shubat, but it is admitted that the normal values were similar than for raw milk [15]. This seemed to be confirmed by correct correlations between raw milk and shubat for zinc and lead. Contrarily, the low relationship for copper was surpriseing.

Concerning organic pollutants in camel milk, at our knowledge, no data are available in the literature. The revealed concentrations of all organic pollutants seem surprisingly low when compared to obvious contamination of the environment in these areas. Thus, the sources of pollution were not always found back in the analyzed milk.

PAH emitting sources correspond to three groups according to industrial activities (energy production, metallurgy, cement works, chemical industries...), urban activities (transport, management and processing of waste) and husbandries (mud spreading, domestic heating) [16]. In addition, dairy animals like camel could be contaminated with PAHs by the air, the soils and the plants. The oil forages in Atyrau do not seem to affect PAH contents in milk of this area. It should be clarified if ingestion behavior of camels would protect them against intake of PAHs deposited on soil or grass. The milks form the South-East oblasts Zhambyl and Shymkent show quite classic PAH-profils with mainly presented light compounds (phenanthrene, fluoranthene and pyrene) but only few heavy compounds. The profile of the Kyzylorda oblast is quite untypical: light compounds do not clearly dominate and nearly all 13 compounds are presented. This profil can not be due to classical observed emitting sources. The absence of hydroxyl metabolites in camel milk seems to confirm that these animals are less exposed than classical dairy ruminants. Differences in the eating behavior could be an explanation.

Pesticides were found mainly in cultivation areas but in concentrations under European thresholds. Especially Chlorothalonil is used against aphids and therefore its occurrence in cotton cultivation areas was not surprising. Only one milk sample shows notable concentrations of indicator PCBs which are transferred up to $80 \%[16,17]$ to milk in ruminants. Nothing is known in what extent such compounds were deposited in the fat matter of camel humps. Moreover, interactions between fat matter 
in the hump and milk fat are not clear nowadays. Thus, camel milk in Kazakhstan being very rich in fat matter, the possibility to export residues of POPs in camel milk is not negligible [18] even if found concentrations remained generally low and under thresholds of European food laws.

Concerning the radionuclides, several analyses were performed in Kazakhstan in human milk because the nuclear tests at Soviet time were common. But no data was available in camel milk. However, the impact of nuclear test on radiological contamination of milk appeared lower than in meat of animals reared in the close polluted areas [15]. According to literature data involving other species, the transfer of radionuclides to milk is less than $1 \%[20]$.

\section{Conclusions}

In spite of the importance of pollution risks in Kazakhstan as mentioned by all the international agencies, the residues of pollutants in camel milk did not appear dramatic although some high values can be observed locally. It appears, however, than the oblast of South-Kazakhstan where the concentration of polluting industries is high, and in a less extent, the Almaty oblast which is highly urbanized, are the most exposed area. However, the metabolism of those pollutants in camel organism and the transfer of those molecules to the consumers remain unknown.

\section{Acknowledgements}

This study was achieved partly with the support of the program ECONET (French Ministry of Foreign Affairs). Our acknowledgement is also for French Embassy in Kazakhstan for their support and help. Thanks to all the labs having contributed to the analysis in CIRAD and ENSAIA-Nancy. And finally, our grateful to the camel farmers having accepted the milk sampling.

\section{REFERENCES}

[1] B. Faye, G. Konuspayeva, S. Messad and G. Loiseau, "Discriminant Milk Components of Bactrian Camel (Camelus Bactrianus), Dromedary (Camelus Dromedarius) and Hybrids," Dairy Science and Technology, Vol. 88, 2008, pp. 607-617. doi:10.1051/dst:2008008

[2] S. Kenzhebulat, B. Ermuhan and A. Tleuov "Composition of Camel Milk and Its Use in the Treatment of Infectious Diseases in Human," Proceeding of 2nd Camelid Conference, Agroeconomics of Camelid Farming, Almaty, September 2000, p. 101

[3] G. Mal, D. S. Sena, V. K. Jain, M. S. Sahani, "Therapeutic Value of Camel Milk as a Nutritional Supplement for Multiple Drug Resistant (MDR) Tuberculosis Patients," Israel Journal of Veterinary Medicine, Vol. 61, 2006, pp.
$88-91$.

[4] P. Licata, D. Trombetta, M. Cristani, F. Giofrè, D. Martino, M. Calò and F. Naccar, "Levels of 'Toxic' and 'Essentials' Metals in Samples of Bovine Milk from Various Dairy Farms in Calabria, Italy," Environment International, Vol. 30, 2003, pp.1-6. doi:10.1016/S0160-4120(03)00139-9

[5] O. Simsek, R. Gültekin, O. Öksüz and S. Kurultay, "The Effect of Environmental Pollution on Heavy Metal Content of Raw Milk," Nahrung, Vol. 44, 2000, pp. 360-363. doi:10.1002/1521-3803(20001001)44:5<360::AID-FOOD $360>3.0 . \mathrm{CO} ; 2-\mathrm{G}$

[6] NF E 1528-2 Aliments Gras-Dosage des Pesticides et des Polychlorobiphényles (PCB)-Partie 2: Extraction de la Matière Grasse, des Pesticides et des PCB, et Détermination de la Teneur en Matière Grasse, 1997. AFNOR, France.

[7] S. Lutz, C. Feidt, F. Monteau, G. Rychen, B. Le Biezc, S. Jurjanz, "Effect of Exposure to Soil-Bound Polycyclic Aromatic Hydrocarbons on Milk Contaminations of Parent Compounds and Their Monohydroxylated Metabolites," Journal of Agricultural and Food Chemistry, Vol. 54, No. 1, 2006, pp. 263-268. doi:10.1021/jf0522210

[8] L. A. Curie "Limits of Qualitative Detection and Quantitative Determination," Analytical Chemistry, Vol. 40, No. 3, 1968, pp. 586-593. doi:10.1021/ac60259a007

[9] I. Bhati and G. N. Choudhri. "Lead Poisoning of Milk-The Basic Need for the Foundation of Human Civilization," Indian Journal of Public Health, Vol. 40, No. 1, 1996, pp. 24-26.

[10] P. Licata, D. Trombetta, M. Cristani, F. Giofre, D. Martino, M. Calo and F. Naccari, "Levels of Toxic and Essentials Metals in Samples of Bovine Milk from Various Dairy Farms in Calabria, Italy," Environmental Research, Vol. 30, No. 1, 2003, pp. 1-6.

[11] A. Meldebekova, E. Diacono, G. Konuspayeva and B. Faye, "Heavy Metals and Trace Elements Content in Camel Milk and Shubat from Kazakhstan," In: B. Faye and Y. Sinyavskiy, Eds., Impact of pollution on animal products, Springer Sciences, Dordrecht, The Netherland, 2008, pp. 117-123. doi:10.1007/978-1-4020-8359-4 12

[12] O. Simsek, R. Gültekin, O. Öksüz and S. Kurultay, "The Effect of Environmental Pollution on Heavy Metal Content of Raw Milk," Nahrung, Vol. 44, 2000, pp. 360-363. doi:10.1002/1521-3803(20001001)44:5<360::AID-FOOD 360>3.0.CO;2-G

[13] S. Dey and D. Swarup, "Lead Concentration in Bovine Milk in India," Archives of Environmental Health, Vol. 51, No. 6, 1996, pp. 478-479. doi:10.1080/00039896.1996.9936050

[14] D. Swarup, R. C. Patra, R. Naresh, P. Kumar and P. Shekhar, "Blood Lead Levels in Lactating Cows Reared around Polluted Localities; Transfer of Lead into Milk," Science of Total Environmental, Vol. 349, No. 1-3, 2005, pp. 67-71. doi:10.1016/j.scitotenv.2004.12.079 
[15] G. Konuspayeva, B. Faye, G. Loiseau, E. Diacono and S. Akhmetsadykova, "Pollution of Camel Milk by Heavy Metals in Kazakhstan," The Open Environmental Pollution \& Toxicology Journal, Vol. 1, 2009, pp. 1-7.

[16] S. Jurjanz, G. Rychen and C. Feidt, "Dairy Livestock Exposure to Persistent Organic Pollutants and Their Transfer to Milk - a Review," In: B. Faye and Y. Sinyavskiy, Eds., Impact of Pollution on Animal Products, Springer Sciences, Dordrecht, The Netherland, 2008, pp. 63-84. doi:10.1007/978-1-4020-8359-4 7

[17] A. Costera, C. Feidt, P. Marchand, B. Le Bizec and G. Rychen, "PCDD/F and PCB Transfer to Milk in Goats Exposed to Long-Term Intake of Contaminated Hay," Chemosphere, Vol. 64, pp. 650-657. doi:10.1016/j.chemosphere.2005.10.052

[18] G. Konuspayeva, B. Faye and G. Loiseau, "The Compo- sition of Camel Milk: A Meta-Analysis of the Literature Data," Journal of Food Composition Analysis, Vol. 22, No. 2, 2008, pp. 95-101. doi:10.1016/j.jfca.2008.09.008

[19] U. Kenesariyev, Z. Bekmagambetova, N. Zhakashov, Y. Sultanaliyev and M. Amrin "Assessing the Hazards of Radiological and Environmental Factors for the Public Health in the Western Kazakhstan," In: B. Faye and Y. Sinyavskiy, Eds., Impact of Pollution on Animal Products, Springer Sciences, Dordrecht, The Netherland, 2008, pp. 47-52. doi:10.1007/978-1-4020-8359-4_5

[20] G. Konuspayeva, B. Faye, G. Loiseau, V. Barci and E. Diacono, "Radionuclides in Camel Milk from Polluted Areas of Kazakhstan," Proceeding of IDF/INRA 1st International Symposium on Minerals and Dairy Products, Saint-Malo, October 2008, p. 53. 